\title{
Isolation and identification of lactic acid bacteria from vegetable-growing soils in Da Lat, Lam Dong
}

\author{
Vuong V. Le, Hai T. Pham, Nguyen T. T. Nguyen, Mai T. N. Dang, \\ Phong V. Nguyen, \& Thanh T. L. Bien* \\ Department of Biotechnology, Nong Lam University, Ho Chi Minh City, Vietnam
}

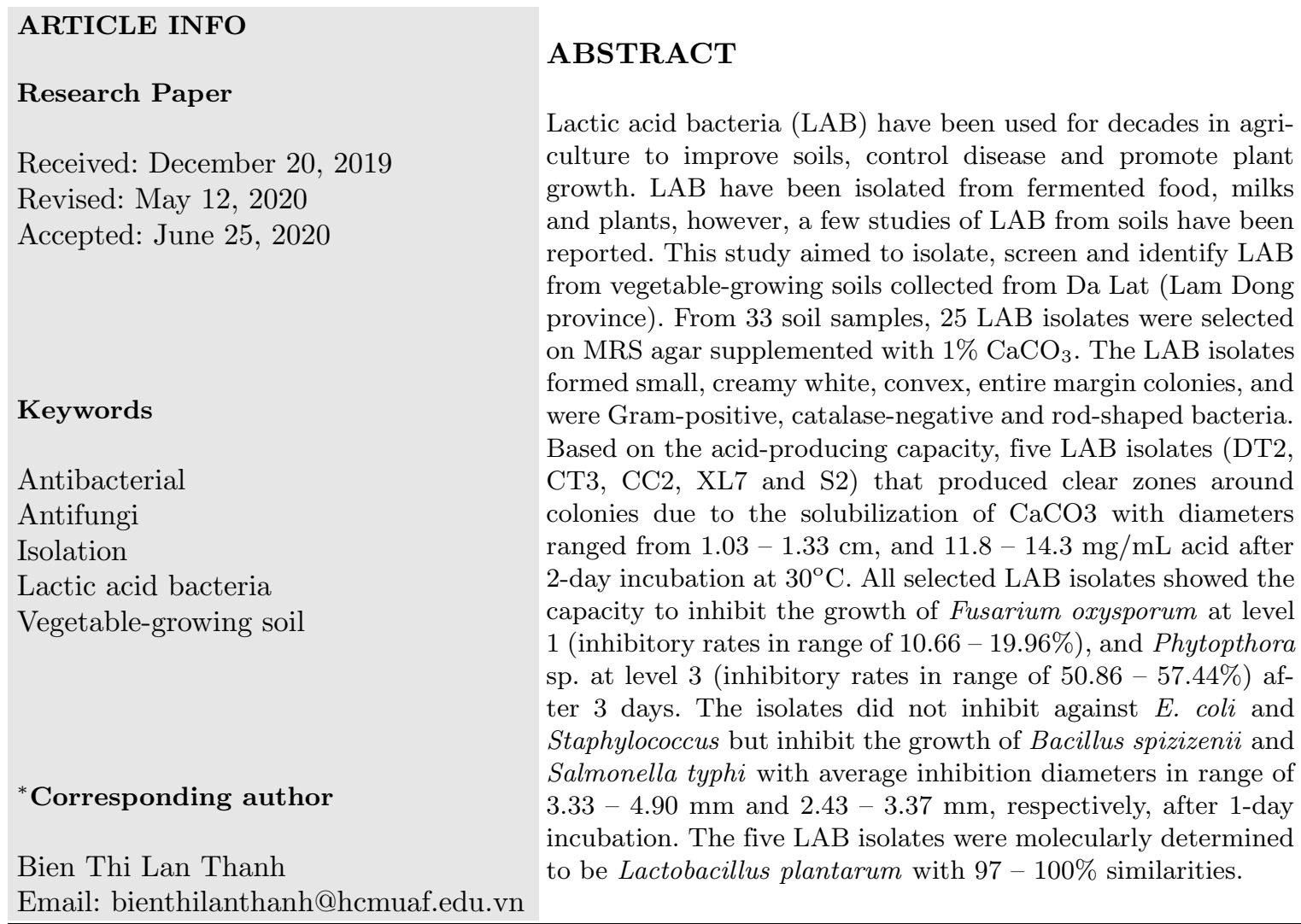

Cited as: Le, V. V., Pham, H. T., Nguyen, N. T. T., Dang, M. T. N., Nguyen, P. V., \& Bien, T. T. L. (2020). Isolation and identification of lactic acid bacteria from vegetable-growing soils in Da Lat, Lam Dong. The Journal of Agriculture and Development 19(4), 1-9. 


\section{Phân lập và xác định vi khuẩn lactic từ đất trồng rau tại Đà Lạt, Lâm Đồng}

\section{Lê Văn Vương, Phạm Thiên Hải, Nguyễn Thị Thảo Nguyên, Đặng Thị Ngọc Mai, Nguyễn Vũ Phong \& Biện Thị Lan Thanh*}

Bộ Môn Công Nghệ Sinh Học, Trường Đại Học Nông Lâm TP.HCM, TP. Hồ Chí Minh

\section{THÔNG TIN BÀI BÁO}

Bài báo khoa học

Ngày nhận: 20/12/2019

Ngày chỉnh sửa: $12 / 5 / 2019$

Ngày chấp nhận: 25/06/2020

\section{Từ khóa}

Đất trồng rau

Kháng khuẩn

Kháng nấm

Phân lập

Vi khuẩn lactic

\section{*Tác giả liên hệ}

Biện Thị Lan Thanh

Email: bienthilanthanh@hcmuaf.edu.vn

\section{TÓM TẮT}

Vi khuẩn lactic (lactic acid bacteria, LAB) được ứng dụng rộng rãi trong nông nghiệp, có tác dụng trong việc cải tạo đất, kiểm soát sinh học, phòng trừ bệnh và kích thích tăng trưởng cây trồng. LAB đã được phân lập từ nhiều nguồn khác nhau như trên thực vật và các sản phẩm lên men chua truyền thống. Tuy nhiên, các nghiên cứu về $\mathrm{LAB}$ trong đất còn hạn chế. Nghiên cứu này được thực hiện nhằm phân lập, tuyển chọn và định danh các chủng LAB có hoạt tính sinh học cao từ mẫu đất trồng rau có tiềm năng ứng dụng sản xuất chế phẩm sinh học góp phần phát triển nền nông nghiệp bền vững. Từ 33 mẫu đất trồng rau thu thập tại thành phố Đà Lạt (Lâm Đồng) đã phân lập được 25 chủng vi khuẩn lactic. Các chủng phân lập có khuẩn lạc nhỏ, tròn, lồi, màu trắng đục, bờ đều, tế bào hình que ngắn kết đôi hoặc xếp chuỗi, Gram dương, catalase âm tính. Dựa vào khả năng sinh acid lactic, đã chọn được 05 chủng LAB (kí hiệu DT2, CT3, CC2, XL7 và S2) có khả năng sinh acid mạnh với đường kính vòng phân giải $\mathrm{CaCO}_{3}$ trên đĩa thạch MRS từ $1,03-1,33 \mathrm{~cm}$ và sinh $11,8-14,3 \mathrm{mg} / \mathrm{mL}$ acid sau 2 ngày ủ ở $30^{\circ} \mathrm{C}$. Tất cả các dòng $\mathrm{LAB}$ tuyển chọn có khả năng kháng Fusarium oxysporum ở mức độ 1 với tỉ lệ ức chế từ 10,66 - 19,96\% và kháng Phytopthora sp. ở mức độ 3 với tỉ lệ ức chế từ 50,86 - 57,44\% sau 3 ngày. Các dòng LAB không thể hiện tính kháng với $E$. coli và Staphylococcus aureus, nhưng kháng với Bacillus spizizenii và Salmonella typhi với đường kính vòng vô khuẩn lần lượt $3,33-4,90 \mathrm{~mm}$ và $2,43-3,37$ $\mathrm{mm}$ sau 1 ngày ủ. Các dòng LAB tuyển chọn có trình tự $16 \mathrm{~S}$ rRNA tương đồng 97 - 100\% với Lactobacillus plantarum.

\section{1. Đặt Vấn Đề}

Vi khuẩn lactic (Lactic acid bacteria, LAB) có mặt khắp nơi trong tự nhiên, có nhiều ứng dụng trong cải thiện sức khỏe con người và vật nuôi, và được xem là an toàn (generally recognized as safe, GRAS) (Stiles, 1996). Nhiều loài LAB đã được chứng minh là có khả năng sản xuất các hợp chất chống lại các vi sinh vật gây bệnh (Chaurasia \& ctv., 2005). LAB trong môi trường tự nhiên được xem như là tác nhân kiểm soát sinh học, cải tạo đất, cung cấp dinh dưỡng, chống lại các vi khuẩn và nấm gây bệnh cây trồng, kích thích nảy mầm hoặc tăng trưởng cây trồng và làm giảm stress do các yếu tố phi sinh học (abiotic stress) (Lamont \& ctv., 2017). Việc sử dụng LAB trong cải tạo đất, kiểm soát bệnh hại, tăng trưởng cây trồng, tăng năng suất, bảo quản nông sản thực phẩm sau thu hoạch là xu hướng tiềm năng để làm giảm hoặc thay thế các loại phân bón, thuốc trừ sâu và các chất bảo quản hóa học ảnh hưởng sức khỏe con người và vật nuôi. Trong các nghiên cứu trước 
đây, rất nhiều dòng LAB đã được phân lập từ sữa và các sản phẩm lên men chua truyền thống. Tuy nhiên, các nghiên cứu về phân lập vi khuẩn trong đất còn rất hạn chế, mặc dù đã có nhiều nghiên cứu chứng minh có sự tồn tại của LAB trong đất (Suzuki \& Yamasato 1994; Yanagida \& ctv., 1997; Chen \& ctv., 2005).

Đề tài được tiến hành nhằm tuyển chọn các dòng LAB trong đất trồng rau có hoạt tính đối kháng đối với vi khuẩn và nấm gây bệnh gây trồng. Kết quả nghiên cứu có thể được ứng dụng để kiểm soát bệnh hại trên rau và bảo quản quản rau an toàn sau thu hoạch.

\section{Vật Liệu và Phương Pháp Nghiên Cứu}

\subsection{Thu mẫu và phân lập $L A B$}

Đất xung quanh vùng rễ cây rau được thu như sau: dùng muỗng sạch loại bỏ lớp đất mặt (khoảng $5 \mathrm{~cm}$ ) và lấy khoảng $100 \mathrm{~g}$ dất, mỗi luống lấy đất ở 5 điểm khác nhau rồi trộn đều và lấy khoảng $100 \mathrm{~g}$ cho vào túi zip sạch và được tính là một mẫu. Ghi rõ thời gian, dịa điểm và loại rau khi thu mẫu. Mẫu đất được trữ trong thùng lạnh $\left(<10^{\circ} \mathrm{C}\right.$, có đá gel $)$, vận chuyển về phòng thí nghiệm và được phân tích trong vòng 2 ngày.

Vi khuẩn lactic được phân lập trên môi trường MRS agar có chứa $1 \% \mathrm{CaCO}_{3}$, ủ ở $30^{\circ} \mathrm{C}$ trong 3 ngày. Các khuẩn lạc nghi ngờ là LAB được chọn lọc dựa vào vòng phân giải $\mathrm{CaCO}_{3}$ trên đĩa môi trường.

\subsection{Kiểm tra khả năng sinh acid lactic của các chủng LAB phân lập}

\subsubsection{Khả năng phân giải $\mathrm{CaCO}_{3}$ trên đĩa thạch}

Khả năng sinh acid của các chủng LAB phân lập được sàng lọc dựa vào sự phân giải $\mathrm{CaCO}_{3}$ trên đĩa thạch được thực hiện theo mô tả của Xiao \& ctv. (2015). Các chủng LAB thuần được nuôi cấy trong $5 \mathrm{~mL}$ môi trường MRS broth ở $30^{\circ} \mathrm{C}$ trong 24 giờ. Hút khoảng $40 \mu \mathrm{L}$ dung dịch vi khuẩn nhỏ vào giếng đã được tạo sẵn trên đĩa môi trường $\mathrm{MRS}$ agar $+1 \% \mathrm{CaCO}_{3}$, mỗi đĩa 3 giếng, và ủ ở $30^{\circ} \mathrm{C}$ trong 2 ngày. Đo đường kính vòng phân giải $\mathrm{CaCO}_{3}$ trên đĩa thạch. Đường kính vòng phân giải được tính theo công thức: $\mathrm{Df}=\frac{(\mathrm{D} 1+\mathrm{D} 2+\mathrm{D} 3)-3 \mathrm{~d}}{3}$, trong đó, $\mathrm{D}$ là đường kính vòng $\mathrm{CaCO}_{3}$ bị phân giải trên đĩa, d là đường kính giếng, Df là vòng phân giải $(\mathrm{cm})$.
Các chủng vi khuẩn tạo vòng phân giải lớn được chọn cho các thí nghiệm tiếp theo.

\subsection{2. Định lượng khả năng sinh acid lactic của các chủng $\mathrm{LAB}$ tuyển chọn}

Lượng acid sinh ra bởi các chủng LAB tuyển chọn được xác định theo phương pháp chuẩn độ bằng $\mathrm{NaOH}$. Các chủng $\mathrm{LAB}$ được nuôi trong 15 $\mathrm{mL}$ môi trường MRS broth ở $30^{\circ} \mathrm{C}$ trong 48 giờ, lắc 150 vòng/phút. Ly tâm thu $10 \mathrm{~mL}$ dịch nổi, bổ sung $20 \mathrm{~mL}$ nước cất vô trùng và $1-2$ giọt phenolphtalein $1 \%$. Chuẩn độ bằng $\mathrm{NaOH} 0,1 \mathrm{~N}$ đến khi xuất hiện màu hồng nhạt bền. Ghi lại thể tích $\mathrm{NaOH}$ đã dùng để chuẩn độ. Lượng acid được tính theo công thức: acid lactic $(\mathrm{mg} / \mathrm{mL})=$ $\left(\mathrm{V}_{\mathrm{NaOH}} \times 0,1 \times 90,08\right) /$ thể tích mẫu (Wakil \& Ajayi, 2013).

\subsection{Khảo sát hoạt tính đối kháng của $\mathrm{LAB}$ tuyển chọn với vi khuẩn và nấm gây bệnh}

Khả năng đối kháng của các dòng LAB chọn lọc được khảo sát với các loài nấm gây bệnh cây trồng như Fusarium oxysporum và Phytophthora sp. và các vi khuẩn gây bệnh như $E$. coli, Salmonella typhi, Bacillus spizizenii và Staphylococcus aureus.

Xác định khả năng đối kháng nấm bệnh của LAB: cấy nấm ( $F$. oxysporum và Phytophthora sp.) vào giữa đĩa môi trường $\mathrm{PDA}$, vi khuẩn lactic (mọc trên môi trường MRS agar sau 2 ngày) được cấy thành hai đường thẳng dài khoảng $2 \mathrm{~cm}$ ở hai bên rìa đĩa, sau đó ủ ở $30^{\circ} \mathrm{C}$ trong 3 ngày. Đĩa đối chứng chỉ cấy nấm, không cấy vi khuẩn. Khả năng ức chế sự tăng trưởng của nấm bệnh (\%) của vi khuẩn lactic được tính theo công thức của Whipps (1987): [(R1-R2)/R1] × 100, trong đó, R1 là bán kính $(\mathrm{cm})$ tăng trưởng của nấm đo ngược hướng không có vi khuẩn và $\mathrm{R} 2$ là bán kính tăng trưởng của nấm đo theo hướng có vi khuẩn. Sự ức chế tăng trưởng (growth inhibition, GI) được tính theo thang từ 0 đến 3 (Korsten \& ctv., 1995): $0=$ không ức chế, $1=1$ dến $25 \%$ GI, $2=26$ đến $50 \%$ GI và $3=51$ đến $75 \%$ GI.

Xác định khả năng kháng khuẩn của LAB: vi khuẩn gây bệnh $(E$. coli, S. typhi, B. spizizenii và $S$. aureus) được nuôi cấy trong $5 \mathrm{~mL}$ môi trường LB lỏng ở $37^{\circ} \mathrm{C}$ qua đêm. $0,1 \mathrm{~mL}$ dịch vi khuẩn (khoảng $10^{7}$ tế bào $/ \mathrm{mL}$ ) được trãi đều trên đĩa môi trường LB agar, sau đó tạo 3 giếng trên mỗi đĩa thạch. $\mathrm{LAB}$ được nuôi cấy trong môi trường MRS broth ở $30^{\circ} \mathrm{C}$ trong 48 giờ, sau đó ly tâm 
thu dịch nổi. $50 \mu \mathrm{L}$ dịch nổi được đặt vào giếng đã tạo ở trên. Đĩa đối chứng làm tương tự nhưng thay dịch vi khuẩn LAB bằng nước cất vô trùng. Ủ các đĩa ở $30^{\circ} \mathrm{C}$ trong 24 giờ và đo đường kính vòng vô khuẩn.

\section{4. Định danh các chủng vi khuẩn lactic chọn lọc bằng sinh học phân tử}

DNA tổng số của các dòng $\mathrm{LAB}$ tuyển chọn được ly trích với DNA Genome Extraction kit theo hướng dẫn của nhà sản xuất, và được dùng làm khuôn mẫu để khuếch đại vùng gen $16 \mathrm{~S}$ rRNA với universal primer: 27F (5'AGAGTTTGATCCTGGCTCAG-3') và 1492R (5'GGTTACCTTGTTACGACTT-3') (Lane, 1991). Thành phần cho $50 \mu \mathrm{L}$ phản ứng gồm $5 \mu \mathrm{L} 10 \times \mathrm{NH}_{4}$ reaction buffer, 3 $\mu \mathrm{L} \mathrm{MgCl}_{2}, 0,5 \mu \mathrm{L}$ dNTP mix, BIOTAQ DNA polymerase $1 \mu \mathrm{L}, 0,5 \mu \mathrm{M}$ forward primer, 0,5 $\mu \mathrm{M}$ reverse primer, 0,5 ng genomic $\mathrm{DNA}$ và nước vừa đủ $50 \mu \mathrm{L}$. Phản ứng $\mathrm{PCR}$ được thực hiện với chu trình nhiệt: tiền biến tính ở $95^{\circ} \mathrm{C}$ trong 3 phút, thực hiện 35 chu kỳ ở $95^{\circ} \mathrm{C}$ trong 15 giây, $55^{\circ} \mathrm{C}$ trong 45 giây, $72^{\circ} \mathrm{C}$ trong 1 phút 30 giây, và giai đoạn hậu kéo dài ở $72^{\circ} \mathrm{C}$ trong 10 phút. Sản phẩm $\mathrm{PCR}$ được phân tích trên gel agarose $1 \%$ trong dung dịch dệm TAE 0,5 $\mathrm{X}$ ở $100 \mathrm{~V}$ trong 30 phút và đọc kết quả dưới tia UV. Sản phẩm PCR được kiểm tra trên gel agarose $1 \%$, sau đó được gửi giải trình tự tại công ty $\mathrm{CP}$ Kỹ thuật và Sinh học ứng dụng Việt Nam. Trình tự 16S rDNA của các chủng LAB phân lập được so sánh trên ngân hàng gene (https://blast.ncbi.nlm.nih.gov/Blast.cgi).

\section{Kết Quả và Thảo Luận}

\subsection{Kết quả phân lập $\mathrm{LAB}$ từ mẫu đất trồng rau}

Vi khuẩn lactic (LAB) có mặt khắp nơi trong tự nhiên như đất, nước, thực vật, sữa, trong đường ruột của người và động vật. Nhiều loài LAB được phát hiện đầu tiên trên thực vật (Mundt, 1970). Đà Lạt có khí hậu miền núi ôn hòa và dịu mát quanh năm, là vùng nông nghiệp trù phú đặc biệt với những sản phẩm rau và hoa, là nơi cung cấp rau cho các khu vực phía Nam và cả nước. Do đó, các vùng đất trồng rau ở Đà Lạt có thể có hệ $\mathrm{LAB}$ đa dạng và phong phú.

Mẫu đất được thu thập từ các vườn trồng rau xà lách, cải thảo, súp-lơ, sú, dâu tây, cải canh,

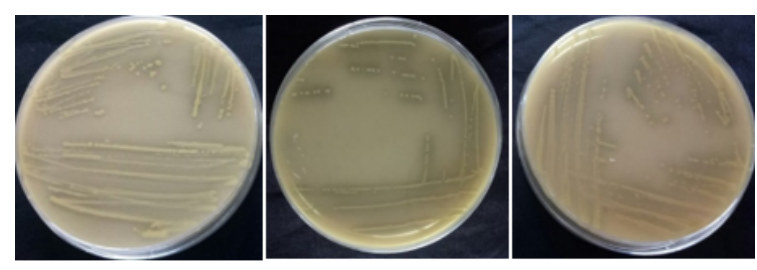

Hình 1. Khuẩn lạc một số dòng vi khuẩn lactic được phân lập từ mẫu đất trồng rau.

tần ô, bó xôi ở phường $5,7,10$ và 11 , thành phố Đà Lạt (Lâm Đồng). Từ 33 mẫu đất đã phân lập được 25 khuẩn lạc có vòng phân giải $\mathrm{CaCO} 3$ xung quanh nghi ngờ là LAB (Hình 1). Các dòng LAB được tuyển chọn có khuẩn lạc nhỏ, tròn, lồi, màu trắng đục, bờ đều, đều là vi khuẩn Gram dương và cho kết quả catalase âm tính. Tế bào nhỏ, hình que, đứng thành đôi, cụm, hoặc thành chuỗi (Hình 2). Các dòng LAB phân lập có các đặc điểm tương tự với vi khuẩn lactic đã được mô tả trước đây (Chen \& ctv., 2005; Ekundayo, 2014).

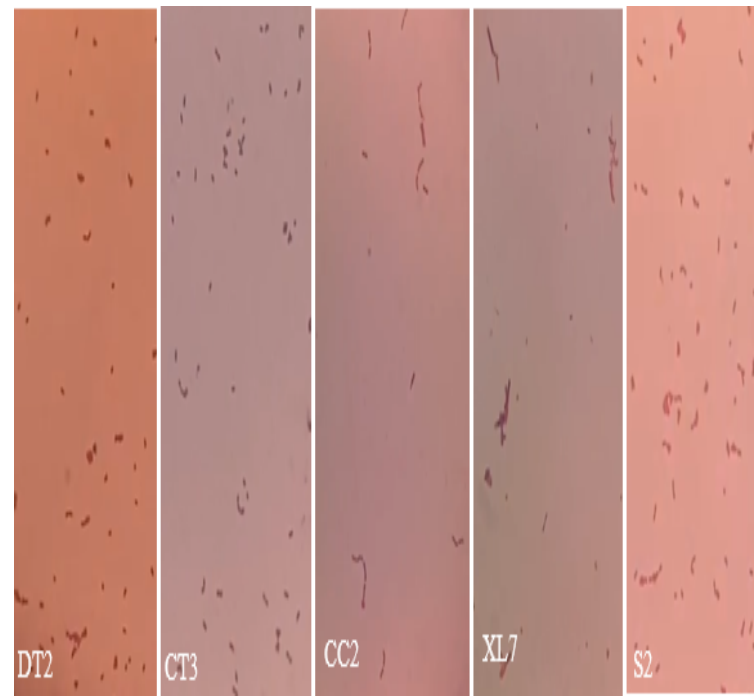

Hình 2. Hình dạng tế bào một số dòng vi khuẩn lactic phân lập.

\subsection{Kết quả thử nghiệm khả năng sinh acid} lactic

Quá trình lên men của $\mathrm{LAB}$ là quá trình chuyển hóa carbohydrate tạo thành acid lactic như là sản phẩm cuối cùng của quá trình lên men (AbdelRahman \& ctv., 2013). Acid lactic từ LAB đã được ứng dụng rộng rãi trong nhiều lĩnh vực, đặc biệt, trong nông nghiệp acid lactic giúp đối kháng 
(A)
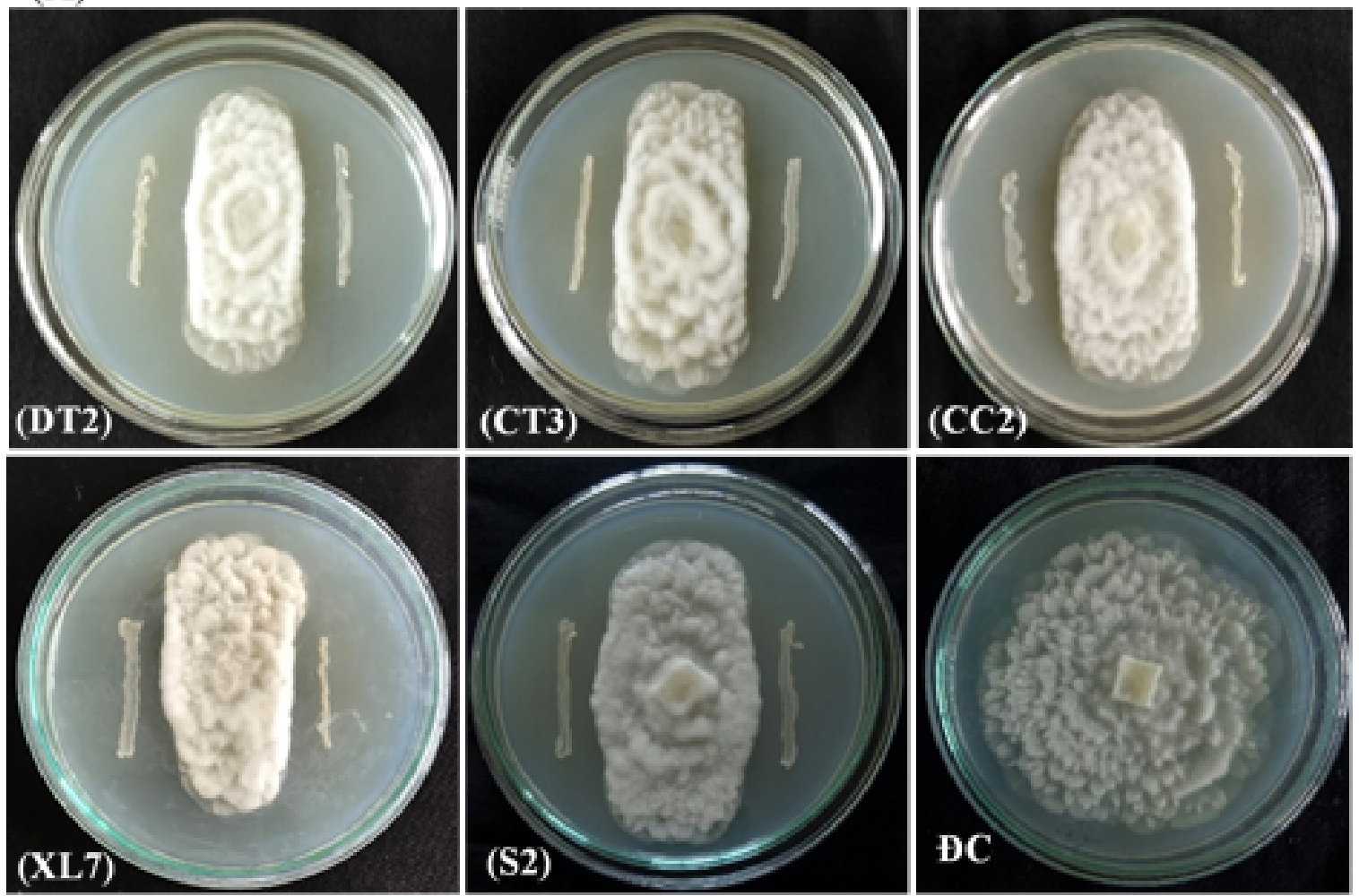

(B)
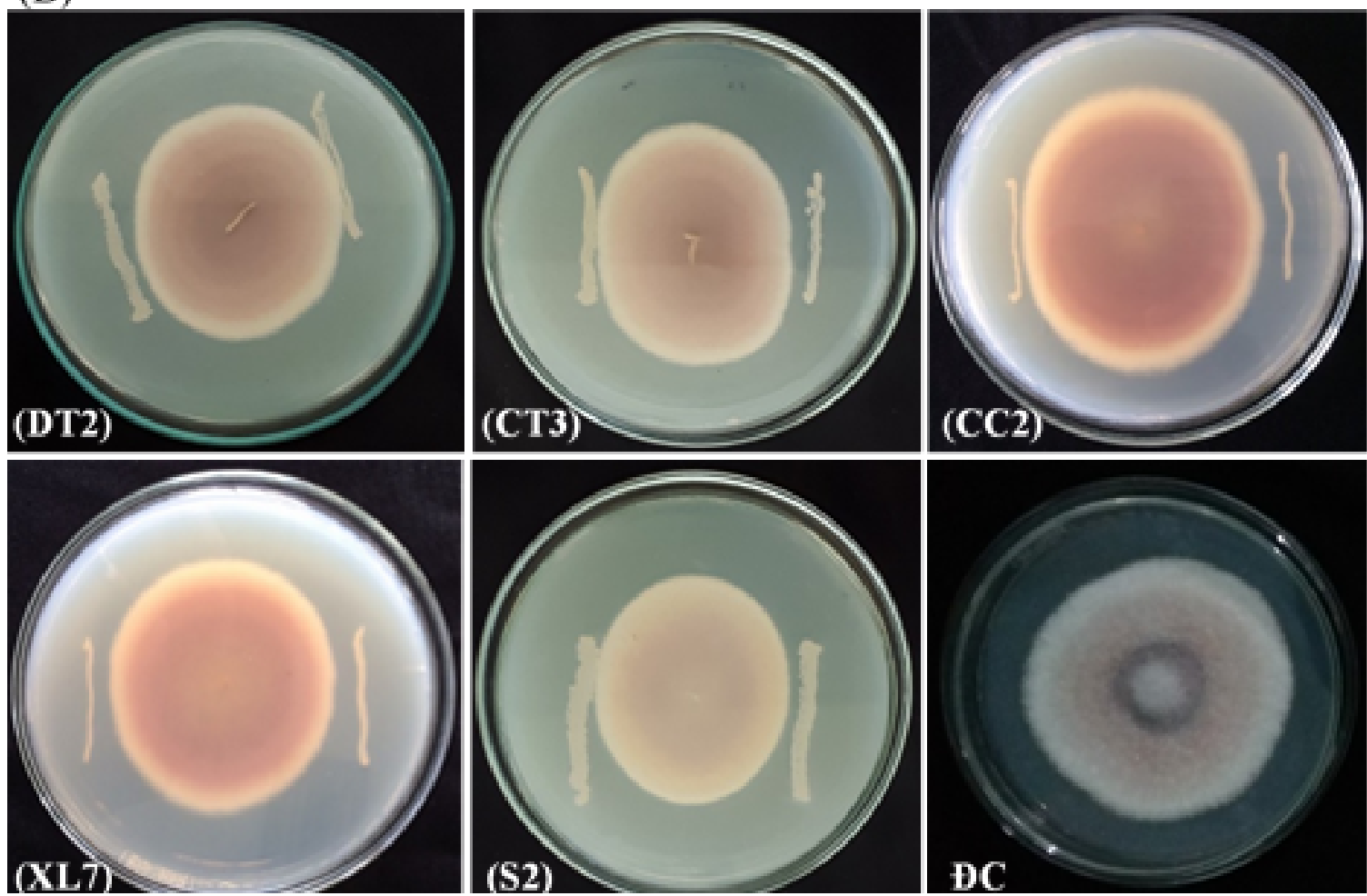

Hình 3. Hoạt tính kháng nấm bệnh của các dòng vi khuẩn lactic tuyển chọn. (A) Phytopthora sp., (B) Fusarium oxysporum. ĐC: đối chứng. 
Bảng 1. Khả năng sinh acid lactic của các dòng vi khuẩn lactic (LAB) tuyển chọn

\begin{tabular}{ccc}
\hline Dòng LAB & Vòng phân giải $\mathrm{CaCO}_{3}(\mathrm{~cm})$ & Acid lactic $(\mathrm{mg} / \mathrm{mL})$ \\
\hline DT2 & 1,03 & 11,8 \\
CT3 & 1,33 & 14,3 \\
CC2 & 1,20 & 13,8 \\
XL7 & 1,27 & 13,8 \\
S2 & 1,07 & 12,0 \\
\hline
\end{tabular}

Bảng 2. Tỉ lệ ức chế nấm bệnh của các dòng vi khuẩn lactic (LAB) tuyển chọn

\begin{tabular}{ccccc}
\hline \multirow{2}{*}{ Dòng LAB } & \multicolumn{2}{c}{$F$. oxysporum } & \multicolumn{2}{c}{ Phytopthora sp. } \\
\cline { 2 - 5 } & Tỉ lệ ức chế $(\%)$ & Mức độ ức chế & Tỉ lệ ức chế $(\%)$ & Mức độ ức chế \\
\hline DT2 & 10,66 & 1 & 57,44 & 3 \\
CT3 & 19,96 & 1 & 56,51 & 3 \\
CC2 & 15,13 & 1 & 54,62 & 3 \\
XL7 & 10,91 & 1 & 50,86 & 3 \\
S2 & 11,73 & 1 & 56,52 & 3 \\
\hline
\end{tabular}

với các mầm bệnh, cải tạo đất, giảm mùi hôi, do đó làm tăng giá trị nông nghiệp (Andreev \& ctv., 2018).

Khả năng sinh acid lactic của các dòng LAB tuyển chọn được xác định dựa vào vòng phân giải $\mathrm{CaCO}_{3}$ trên đĩa thạch và được định lượng dựa theo phương pháp chuẩn độ $\mathrm{NaOH}$. Vòng phân giải $\mathrm{CaCO}_{3}$ của các dòng LAB sau 2 ngày dao động từ $0,87-1,33 \mathrm{~cm}$, tương ứng với hàm lượng acid sinh ra từ $11,4-14,3 \mathrm{mg} / \mathrm{mL}$. Trong đó, 5 chủng có khả năng sinh acid cao nhất (Bảng 1) được tuyển chọn cho các thí nghiệm sau.

\subsection{Kết quả khảo sát tính kháng của LAB đối với nấm và vi khuẩn gây bệnh}

Hoạt tính kháng nấm của các dòng LAB tuyển chọn được khảo sát với Phytopthora sp. và Fusarium oxysporum, tính kháng khuẩn được khảo sát với vi khuẩn Gram âm gồm $E$. coli và Salmonella typhi và vi khuẩn Gram dương gồm Bacillus spizizenii và Staphylococcus aureus. Kết quả khảo sát tính kháng nấm được thể hiện ở Bảng 2 và Hình 3 , và tính kháng khuẩn thể hiện ở Bảng 3 . Các LAB tuyển chọn thể hiện tính kháng $F$. oxysporum (với tỉ lệ ức chế từ 10,66 - 19,96\%, mức độ 1) thấp hơn so với Phytopthora sp. (với tỉ lệ ức chế từ 50,86 - 57,44\%, mức độ 3 ).

Nhờ khả năng sản xuất các acid hữu cơ (như acid lactic hoặc probionic) và các hợp chất kháng sinh (như bacteriocin), LAB được sử dụng như là tác nhân kiểm soát mầm bệnh trên cây trồng (Daranas \& ctv., 2019), mầm bệnh trong đất (Lutz \& ctv., 2012) và kiểm soát các bệnh sau
Bảng 3. Khả năng kháng khuẩn của các dòng vi khuẩn lactic (LAB) phân lập

\begin{tabular}{ccc}
\hline \multirow{2}{*}{ Dòng LAB } & \multicolumn{2}{c}{ Đường kính vòng vô khuẩn $(\mathrm{mm})$} \\
\cline { 2 - 3 } & B. spizizenii & S. typhi \\
\hline DT2 & 4,90 & 2,43 \\
CT3 & - & 3,37 \\
CC2 & 3,67 & 3,00 \\
XL7 & 3,50 & 3,23 \\
S2 & 3,33 & 3,17 \\
\hline
\end{tabular}

-: không có vòng vô khuẩn.

thu hoạch (Caplice \& Fitzgerald, 1999).

Trước đó, Wang \& ctv. (2012) đã thu nhận được hai hợp chất kháng nấm (Benzeneacetic acid và 2-propenyl ester) từ Lactobacillus plantarum IMAU10014 có hoạt tính phổ rộng kháng Botrytis cinerea, Glomerella cingulate, Phytophthora drechsleri Tucker, Penicillium citrinum, Penicillium digitatum và Fusarium oxysporum. Zebboudj \& ctv. (2014) đã báo cáo rằng, 4 dòng LAB gồm Lactococcus lactis subsp. lactis, Lactococcus lactis subsp. lactis biovar. diacetylactis, Leuconostoc mesenteroides subsp. mesenteroides và Leuconostoc mesenteroides subsp. mesenteroides biovar. dextranicum có khả năng ức chế tăng trưởng của $F$. oxysporum $\mathrm{f}$. sp. albedinis từ 13,51 - 40,29\% trên môi trường PDA. Năm 2018, Juodeikiene \& ctv. đã chứng minh các dòng LAB Lactobacillus sakei KTU05-6, Pediococcus acidilactici KTU05-7, và Pediococcus pentosaceus có khả năng làm giảm độc tố của Fusarium trong quá trình nảy mầm của hạt lúa mì lên đến $73 \%$, đồng thời các dòng LAB này còn thể hiện tính 
Bảng 4. Kết quả so sánh trình tự $16 \mathrm{~S}$ rDNA của các dòng vi khuẩn lactic $(\mathrm{LAB})$ tuyển chọn trên ngân hàng gene

\begin{tabular}{|c|c|c|c|}
\hline STT & Dòng LAB & Loài tương đồng (\%) & Số hiệu \\
\hline \multirow{5}{*}{1} & \multirow{5}{*}{ DT2 } & Lactobacillus plantarum strain T17 (100\%) & MG739432.1 \\
\hline & & Lactobacillus plantarum strain MKU9 (100\%) & MT549143.1 \\
\hline & & Lactobacillus plantarum strain MKU7 (100\%) & MT549142.1 \\
\hline & & Lactobacillus plantarum strain $8941(100 \%)$ & MT539056.1 \\
\hline & & Lactobacillus plantarum strain $8283(100 \%)$ & MT538969.1 \\
\hline \multirow{5}{*}{2} & \multirow{5}{*}{ CT3 } & Lactobacillus plantarum strain MKU9 (99\%) & MT549143.1 \\
\hline & & Lactobacillus plantarum strain MKU7 (99\%) & MT549142.1 \\
\hline & & Lactobacillus plantarum strain $8941(99 \%)$ & MT539056.1 \\
\hline & & Lactobacillus plantarum strain $8283(99 \%)$ & MT538969.1 \\
\hline & & Lactobacillus plantarum strain $8194(99 \%)$ & MT538940.1 \\
\hline \multirow{5}{*}{3} & \multirow{5}{*}{$\mathrm{CC} 2$} & Lactobacillus plantarum strain Sourdough_E011 (97\%) & MG754687.1 \\
\hline & & Lactobacillus plantarum strain Sourdough_E01 (97\%) & MG754679.1 \\
\hline & & Lactobacillus plantarum strain Sourdough_E9 (97\%) & MG754548.1 \\
\hline & & Lactobacillus plantarum strain RK37 (97\%) & KF225698.1 \\
\hline & & Lactobacillus plantarum strain FQ011 (97\%) & KF418818.1 \\
\hline \multirow{5}{*}{4} & \multirow{5}{*}{ XL7 } & Lactobacillus plantarum strain MKU9 (100\%) & MT549143.1 \\
\hline & & Lactobacillus plantarum strain MKU7 (100\%) & MT549142.1 \\
\hline & & Lactobacillus plantarum strain $8941(100 \%)$ & MT539056.1 \\
\hline & & Lactobacillus plantarum strain $8283(100 \%)$ & MT538969.1 \\
\hline & & Lactobacillus plantarum strain $8194(100 \%)$ & MT538940.1 \\
\hline \multirow{5}{*}{5} & \multirow{5}{*}{$\mathrm{S} 2$} & Lactobacillus plantarum strain IDK $120(99 \%)$ & MT211513.1 \\
\hline & & Lactobacillus plantarum strain R12 $(99 \%)$ & MG841152.1 \\
\hline & & Lactobacillus plantarum strain MKU9 (99\%) & MT549143.1 \\
\hline & & Lactobacillus plantarum strain MKU7 (99\%) & MT549142.1 \\
\hline & & Lactobacillus plantarum strain 8941 (99\%) & MT539056.1 \\
\hline
\end{tabular}

kháng nấm phổ rộng, đặc biệt là với $F$. culmorum và $F$. poae.

Các dòng LAB khảo sát không thể hiện tính kháng với $E$. coli và $S$. aureus, nhưng kháng với B. spizizenii và $S$. typhi với đường kính vòng vô khuẩn trung bình lần lượt là $3,33-4,90 \mathrm{~mm}$ và $2,43-3,37 \mathrm{~mm}$ được quan sát thông qua vòng vô khuẩn trên đĩa thạch sau 24 giờ, trong đó có dòng CC2 không thể hiện tính kháng với $B$. spizizenii (Bảng 3).

\subsection{Kết quả định danh các dòng $L A B$ được tuyển chọn}

Các dòng LAB tuyển chọn được định danh bằng cách giải trình tự vùng gene $16 \mathrm{~S}$ rRNA sau khi được khuếch đại với cặp universal primer $27 \mathrm{~F}$ và 1492R bằng PCR (Hình 4). Kết quả so sánh trình tự $16 \mathrm{~S}$ rDNA của các chủng $\mathrm{LAB}$ tuyển chọn được thể hiện ở Bảng 4.

Theo kết quả so sánh trên ngân hàng gen, cả năm mẫu LAB tuyển chọn đều có trình tự $16 \mathrm{~S}$
rDNA tương đồng với loài Lactobacillus plantarum từ 97 đến 100\%. Kết quả này tương đồng với các đặc điểm về hình thái học của các chủng LAB tuyển chọn, là các vi khuẩn có khuẩn lạc nhỏ dạng điểm (punctiform), lồi (convex), bờ đều (entire margin), màu trắng đục (opaque) (Hình 1); bắt màu Gram dương, tế bào hình que, xếp thành từng cặp, từng cụm, hoặc thành chuỗi có chiều dài khác nhau (Hình 2). Đặc điểm hình dạng và tế bào của các chủng $\mathrm{LAB}$ tuyển chọn trong nghiên cứu này cũng phù hợp với mô tả về vi khuẩn L. plantarum của Qian \& ctv. (2018) và Talashi $\&$ Sharma (2019). Trước đó, Yanagida \& ctv. (2006) cũng đã phân lập được 3 chủng $L$. plantarum trong 42 mẫu vi khuẩn từ các mẫu đất có khả năng sinh acid bao gồm $L$. plantarum C072201; L. plantarum C101904; L. plantarum C121204. Một nghiên cứu khác của tác giả Ekundayo (2014) đã phân lập 11 dòng Lactobacillus từ đất xung quanh vùng rễ cây ổi và bắp, trong đó có 3 dòng là L. plantarum. L. plantarum thường được tìm thấy trong tự nhiên, có tầm quan trọng công nghiệp như là một yếu tố quan trọng của các 
chất lên men được sử dụng trong các sản phẩm thực phẩm lên men chứa men vi sinh, được tiêu thụ trên toàn thế giới.

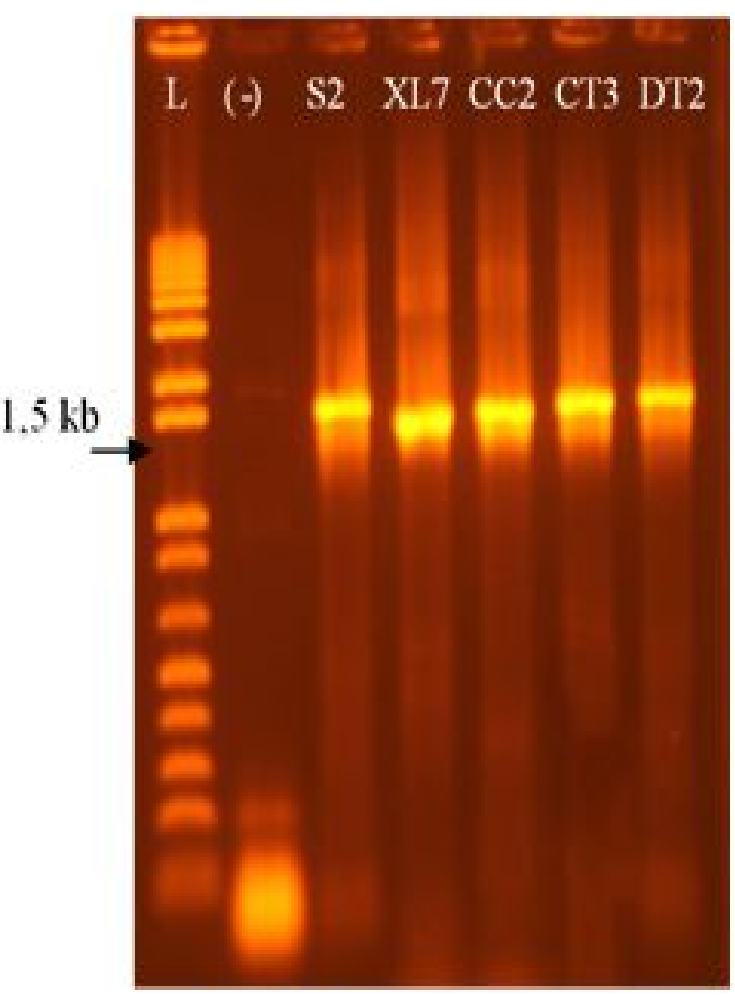

Hình 4. Kết quả khuếch đại vùng gene $16 \mathrm{~S}$ rRNA của các dòng vi khuẩn lactic tuyển chọn. L: thang DNA, (-) đối chứng âm.

\section{Kết Luận}

Từ 33 mẫu đất từ các vườn rau tại Đà Lạt đã tuyển được 5 dòng LAB (DT2, CT3, CC2, XL7, và $\mathrm{S} 2$ ) có khả năng kháng Fusarium oxysporum với tỉ lệ ức chế từ 10,66 - 19,96\% và kháng $P h y$ topthora sp. với tî̉ lệ ức chế từ 50,86 - 57,44\%. Các dòng LAB không thể hiện tính kháng với $E$. coli và Staphylococcus, nhưng kháng đồng thời Bacillus spizizenii (trừ dòng $\mathrm{CC} 2$ ) và Salmonella typhi. Các dòng LAB này có trình tự $16 \mathrm{~S}$ rDNA tương đồng với chủng Lactobacillus plantarum từ $97-100 \%$.

\section{Lời Cảm Ơn}

Nghiên cứu này là một phần của đề tài khoa học và công nghệ cấp cơ sở mã số CS-SV18CNSH-03 được cấp kinh phí bởi Trường Đại học Nông Lâm TP. Hồ Chí Minh.

\section{Tài Liệu Tham Khảo (References)}

Abdel-Rahman, M. A., Tashiro, Y., \& Sonomoto, K. (2013). Recent advances in lactic acid production by microbial fermentation processes. Biotechnology Advances $31,877-902$.

Andreev, N., Ronteltap, M., Boincean, B., \& Lens, P. N. L. (2018). Lactic acid fermentation of human excreta for agricultural application. Journal of Environmental Management 206, 890-900.

Caplice, E., \& Fitzgerald, G. F. (1999). Food fermentations: role of microorganisms in food production and preservation. International Journal of Food Microbiology 50, 131-149.

Chaurasia, B., Pandey, M., \& Palni, M. (2005). Diddusible and volatile compounds produced by an antagonistic Bacillus subtilis strain couse structural deformations in pathogenic fungi in vitro. Microbiology Research $160,75-81$.

Chen, Y. S., Yanagida, F., \& Shinohara, T. (2005). Isolation and identification of lactic acid bacteria from soil using an enrichment procedure. Letters in Applied Microbiology 40, 195-200.

Daranas, N., Roselló, G., Cabrefiga, J., Donati, I., Francés, J., Badosa, E., Spinelli, F., Montesinos, E., \& Bonaterra, A. (2019). Biological control of bacterial plant diseases with Lactobacillus plantarum strains selected for their broad-spectrum activity. Annals of Applied Biology 174, 92-105.

Ekundayo, F. O. (2014). Isolation and identification of lactic acid bacteria from rhizosphere soils of three fruit trees, fish and ogi. International Journal of Current Microbiology and Applied Sciences 3(3), 991e998.

Juodeikiene, G., Bartkiene, E., Cernauskas, D., Cizeikiene, D., Zadeike, D., Lele, V., \& Bartkevic, V. (2018). Antifungal activity of lactic acid bacteria and their application for Fusarium mycotoxin reduction in malting wheat grains. $L W T$ 89, 307-314.

Lamont, J. R., Wilkins, O., Bywater-Ekegard, M., \& Smith, D. L. (2017). From yogurt to yield: Potential applications of lactic acid bacteria in plant production. Soil Biology and Biochemistry 111, 1-9.

Lane, D. J. (1991). 16S/23S rRNA sequencing. In Stackebrandt, E., \& Goodfellow, M. (Eds.). Nucleic acid techniques in bacterial systematics (115-175). New York, USA: John Wiley \& Sons.

Lutz, M. P., Michel, V., Martinez, C., \& Camps, C. (2012). Lactic acid bacteria as biocontrol agents of soil-borne pathogens. Biological Control of Fungal and Bacterial Plant Pathogens IOBC-WPRS Bulletin 78, 285-288.

Korsten, L., De Jager, E. S., De Villiers, E. E., Lourens, A., \& Wehner, F. C. (1995). Evaluation of bacterial epiphytes isolated from avocado leaf and fruit surfaces for biocontrol of avocado postharvest diseases. Plant Disease 79, 1149-1156. 
Mundt, J. O. (1970). Lactic acid bacteria associated with raw plant food material. Journal of Milk and Food Technology 33, 550-553.

Qian, Y., Long, X., Pan, Y., Li, G., \& Zhao, X. (2018). Isolation and identification of lactic acid bacteria ( $L a c$ tobacillus plantarum YS2) from yak yogurt and its probiotic properties. Biomedical Research 29(4), 815-820.

Stiles, M. E. (1996). Biopreservation by lactic acid bacteria. Antonie van Leuwenhoek 70, 331-345.

Suzuki, T., \& Yamasato, K. (1994). Phylogeny of sporeforming LAB based on 16S rRNA gene sequences. FEMS Microbiol Lett 115, 13-17.

Talashi, S., \& Sharma N. (2019). Isolation of Lactobacillus plantarum from human breast milk with probiotic and medical attributes. Acta Scientific Microbiology 2(6), 163-171.

Wakil, S. M., \& Ajayi, O. O. (2013). Production of lactic acid from starchy-based food substrates. Journal of Applied Biosciences 71, 5673-5681.

Wang, H., Yan, Y., Wang, J., Zhang, H., \& Qi, W. (2012). Production and characterization of antifungal compounds produced by Lactobacillus plantarum IMAU10014. PLoS One 7(1) e29452.

Whipps, J. M. (1987). Effect of media on growth and interactions between a range of soil-borne glasshouse pathogens and antagonistic fungi. New Phytologist $107,127-142$.
Xiao, P., Huang, Y., Yang, W., Zhang, B., \& Quan, X. (2015). Screening lactic acid bacteria with high yielding-acid capacity from pickled tea for their potential uses of inoculating to ferment tea products. Journal of Food Science and Technology 52(10), 6727-6734.

Yanagida, F., Chen, Y., \& Shinohara, T. (2006). Searching for bacteriocin-producing lactic acid bacteria in soil. The Journal of General and Applied Microbiology 52, 21-28.

Yanagida, F., Suzuki, K., Kozaki, M. \& Komagata, K. (1997). Proposal of Sporolactobacillus nakayamae subsp. nakayamae sp. nov., subsp. nov., Sporolactobacillus nakayamae subsp. racemicus subsp. nov., Sporolactobacillus terrae sp. nov., Sporolactobacillus kofuensis sp. nov., and Sporolactobacillus lactosus sp. nov. International Journal of Systematic Bacteriology 47, 499-504.

Zebboudj, N., Yezli, W., Hamini-Kadar, N., Kihal, M., \& Henni, J. E. (2014). Antifungal activity of lactic acid bacteria against Fusarium oxysporum f. sp. albedinis isolated from diseased date palm in South Algeria. International Journal of Biosciences 5, 99-106. 